\title{
pÿChildren s Initiatives in the Finnish Early Childhood Education Context
}

\section{Kangas, Jonna}

Palgrave Macmillan

2019

pÿKangas , J \& Lastikka , A-L 2019, Children s Initiatives in the Finnish Early Childhood Education Context . in S Garvis, H Harju-Luukkainen, S Sheridan \& P Williams (eds), Nordic Families, Children and Early Childhood Education. Studies in Childhood and Youth , Palgrave Macmillan , Cham , pp. 15-36 . https://doi.org/10.1007/978-3-030-16866-7_2

http://hdl.handle.net/10138/307749

https://doi.org/10.1007/978-3-030-16866-7_2

unspecified

acceptedVersion

Downloaded from Helda, University of Helsinki institutional repository.

This is an electronic reprint of the original article.

This reprint may differ from the original in pagination and typographic detail.

Please cite the original version. 
In: Garvis, S., Harju-Luukkainen, H., Sheridan, S. \& Williams, P. (eds.). Nordic Families, Children and Early Childhood Education. Cham: Palgrave Macmillan, p. 15-36 22 p. (Studies in Childhood and Youth).

\title{
Children's Initiatives in the Finnish Early Childhood Education Context
}

\author{
Kangas, Jonna \& Lastikka, Anna-Leena
}

\begin{abstract}
Pedagogical practices in early childhood education, which embrace children's initiatives and agency, have been found to have an effect on children's learning and competence skills. These initiatives can be seen crucial for children's wellbeing and self-motivation; however, children's initiatives are sometimes considered only wants, and children incapable to express meaningful initiatives in educational settings. In this paper we introduce children's initiatives in their educational society and examine the gap between children's experiences and teachers' observations. Children' initiatives exist in many different occasions with the daily practices and through the processes that nourish motivation and create meaning-making through actions, it is essential to focus on children's participation aiming to promote children's agency and motivation
\end{abstract}

\section{Introduction}

The Nordic discourses in childhood, especially in early childhood, emphasize the competent child, who is able to express desires, perceptions, and interests. In the Nordic curricula, children are seen as active, competent, developing and learning. (Alasuutari, 2014) This reflect the viewpoint of sociological research of childhood where children are sen active agents of their live (Corsaro, 2011). Furthermore, equality and the ideal of universal access of ECE services is central in the Nordic educational policies (Karila, 2012). Children's active participation has been a prevalent theme in the educational research for over ten years. In the Finnish Early Childhood Education (ECE) context, which is the context of this chapter, the recently revised National Core Curriculum for early years (Finnish National Agency for Education, 2016) emphasizes children's participation, which e.g. involves that educators listen, react and plan according to children's initiatives.

Our starting point for this research is that when teachers pay attention to children's ideas and wishes, the curriculum is motivating for children as their ownership of it becomes clearer (e.g. Lastikka \& Kangas, 2017; Sheridan \& Pramling Samuelsson, 2001). We rely on to the new sociology of childhood (Corsaro, 2011) and the socio-cultural learning paradigm (Kumpulainen \& al., 2014; Rogoff, 2008), where children are considered as active agents of their own lives and reproducers of the culture. Through agency children can gain capacity to have some control and to be able to exert influence on their lives (Hilppö 2016; Corsaro, 2011). In our research, children's initiatives towards their own actions, their peers and teachers are considered as active meaning-making through which children shape their environments and reproduce school's culture around them. We follow the research tradition of early childhood education science, where the research focus is at interaction between child, teachers and learning environment, and reflecting and developing the pedagogical practices. The complex nature of childhood (and our lives) and the diversity of being a human in postmodern era is reflected in a new tradition of Early Childhood Education studies together with the voice of participant and many-sided description of everyday life in classrooms. (Hatch, 2013).

Although pedagogical practices, which embrace children's initiatives, have been found to have an effect on children's participation skills, the research on children's initiatives and their role in learning and pedagogical planning in early childhood education is scarce. For example, 
In: Garvis, S., Harju-Luukkainen, H., Sheridan, S. \& Williams, P. (eds.). Nordic Families, Children and Early Childhood Education. Cham: Palgrave Macmillan, p. 15-36 22 p. (Studies in Childhood and Youth).

already in 1978, Straughan stated that children do express wishes, wants and initiatives, which promote children's motivation towards learning. Therefore, our particular interest is to investigate ECE teachers' and children's conceptions of initiatives. In this chapter, we will combine results of a qualitative study of 4- to 6-year-old children's $(\mathrm{N}=94)$ initiatives and teachers' $(\mathrm{N}=143)$ conceptions of children's everyday initiatives in the context of Finnish early childhood education in order to promote children's learning by contributing to the development of participatory and democratic early childhood education pedagogy and research. Our intention is to answer to the following research questions:

1. To whom are children expressing their initiatives in educational settings?

2. What kind of initiatives children make in educational settings?

3. What kind of gaps of participation can be identified from descriptions of children's initiatives?

\section{Theoretical framework}

Our study supports the idea of Sheridan and Pramling Samuelsson (2001) that children should feel that they participate, express their views and ideas on equal terms, as well as become involved in democratic processes and actively have an influence on their own learning process. Consequently, our theoretical framework supports children's participation and motivational learning, which are complementary to each other. Next, we will discuss the frameworks and the theoretical underpinnings of our study. In the last part of the theoretical framework, we will introduce the educational discussion about everyday interactions between teachers and children and the framework of participatory pedagogy.

\section{Children's participation}

In this study, children's participation is viewed through the participatory learning approach where children are seen as active agents of their learning and meaning makers of their social interactions (Kangas, Venninen \& Ojala, 2016; Berthelsen, 2009). This relies strongly on the socio-cultural learning paradigm (Rogoff, 2008) in which children are viewed as active learners, agents of their lives and reproducers of the culture instead of being needy and helpless beings (Corsaro, 2011; Piaget, 1976). In general, participation can be seen as a developing cultural aspect within the community of children and educators participating in everyday practices (Kangas, 2016; Kumpulainen \& al. 2014).

Participation is also associated with liking school and higher perceived academic performance, better self-rated health, higher life satisfaction and greater reported happiness together with better self-regulation (Kangas, 2016; De Ro'iste et al., 2011). The research of Sheridan and Samuelsson (2001) also highlight that it is vital for the children to participate in decision-making in their early childhood education settings. For example, Shier (2001) has shown that becoming listened to and having opportunities to express opinions (i.e. to express initiatives) are prior to actual decision-making and sharing of power. This creates a feeling of belonging where the joy of learning emerges, and motivation and resilience are developing. (Kangas, Venninen \& Ojala, 2016; Kumpulainen \& al., 2014).

Finally, empowerment of an individual child is considered through the powershifting from an institutional level to an individual level. In early childhood education, children's participation 
In: Garvis, S., Harju-Luukkainen, H., Sheridan, S. \& Williams, P. (eds.). Nordic Families, Children and Early Childhood Education. Cham: Palgrave Macmillan, p. 15-36 22 p. (Studies in Childhood and Youth).

has been in the focus of development and administrative procedures, and thus considered supporting better decision-making by adults and improving policies aimed at children (Mayall 1999).

\section{Motivation and learning}

Our approach to learning promotes the view that a learning environment in which children have choices and are involved in individual and shared decisions, are crucial for learning and intrinsic motivation (see Sheridan \& Pramling Samuelsson, 2001). Motivation is a central factor, because it is fundamental for biological, cognitive and social regulation. (Ryan \& Deci, 2000) In the self-determination theory of motivation and personality, Ryan and Deci (2000) have found three psychological needs, which are crucial for intrinsic self-motivation and personal wellbeing. These are autonomy, competence, and relatedness. It is important to highlight that autonomy does not imply independence but a feeling to have a choice and a free will. Following, the need for competence is satisfied, when children feel that they have developed new skills and that they are capable of accomplishing activities or tasks. The need for relatedness refers to the need of feeling belongingness and connectedness with others. Also Straughan (1978) states that children's initiatives and 'wants' are educationally valuable, because these interests can be used effectively sustaining child's interest in learning. Straughan separates the concepts of wanting something as inner motivation from other motivational aspects of things which children consider to justify or require their actions (1978).

The three psychological needs of autonomy, competence, and relatedness, are similar to the key elements of the participatory pedagogy. Also all contemporary theories of motivation include a concept, which is related to beliefs about competence (Cook \& Artino, 2016). Furthermore, in the self-determination theory, as well as in the participatory pedagogy, the social environment and the feeling of togetherness and belongingness play an important role. Being attentive to children's intentions and interests enables collaborative actions and encounters between children and educators (Cheeseman \& Sumsion, 2016). Therefore, we see that the role of an educator is crucial, because of the decision to seize or not on children's initiatives towards shared actions (see Rutanen, 2012).

\section{The Pedagogical concerns of interactions in the classroom}

From the pedagogical viewpoint, participation in ECE contexts can be seen as a shared activity with children and adults to interpret the world. However, this requires that adults respect children and are interested in their experiences, opinions and are willing to answer their initiatives (Karlsson, Weckström \& Lastikka 2018; Leinonen \& Venninen 2012). This means that children are assumed to have a chance to be listened to, and to have opportunities for independent initiatives (Kangas 2016). In early childhood education, children's participation has been found to occur within the interaction between a child and a learning environment including peers and teachers (Woodhead 2015). Young children's participation is seen as developing a set of skills to have influence and take responsibility (Kangas 2016).

Additionally, it is important to understand that while policy-makers, teachers and even parents are aiming to make decisions "in the best interests of children", they may end up to abuse children rights to participate in the decisions concerning their own lives (Woodhead, 2015). 
In: Garvis, S., Harju-Luukkainen, H., Sheridan, S. \& Williams, P. (eds.). Nordic Families, Children and Early Childhood Education. Cham: Palgrave Macmillan, p. 15-36 22 p. (Studies in Childhood and Youth).

Children's expressions of their initiatives are traditionally interpreted as desires or ideas for short-term pleasure. For example, Thomas \& Kane (1998) had stated that children's ideas may be in conflict with their 'best interests' (see also Straughan 1978). This kind of way of thinking refers to the traditional psychological view to children as needy and non-competent individuals, who cannot make decisions or take initiatives concerning their lives (Mayall 1999).

It might also be difficult for teachers to facilitate children's motivation through participation, because they are unsure of what things children can decide and how to include children in decision-making (Leinonen \& Venninen 2012; Sheridan \& Samuelsson 2001). It has been found that education practices are empowering only when they are planned and developed together with the children, and not prepared by adults and handed down to the children (Hilppö 2016). This co-operation for making shared curriculum become possible, when teachers listen and observe children's initiatives and empower children into joint decision-making process (see Leinonen \& Venninen 2012).

Furthermore, it has been shown that children's initiatives are sometimes considered less important than adults in educational context (Aras 2016; Leinonen \& al. 2014; Straughan 1978). On the other hand, Hilppö (2016) states that if professionals are willing to support and promote children's sense of agency, more consideration should be given to the small agentic moments in the daily lives of children.

\section{The Finnish ECE context}

\section{Methods}

In Finland, early childhood education and care for 0-5 -year-old children, is guided by the National Core Curriculum for ECE (Finnish National Agency for Education, 2016) and the Early Childhood Education and Care Act. In general, the Finnish early childhood education system is built on a holistic view of children's growth, development, and learning through play. Children's participation is highlighted: children's, personnel's and guardians' initiatives, perceptions and opinions are appreciated. This in turn involves that participatory practices are promoted through experiences of being heard and listened to (Kangas \& al. 2016). Children's opinions are seen important in planning, implementing and assessing early childhood education.

\section{Data collection}

The research data consists of two data sets. Teachers' $(\mathrm{N}=1150)$ conceptions of children's participation in their classrooms is collected through a survey questionnaire where they explained in open-ended questions about different kinds of independent initiatives, ideas and wishes that teachers had been observing from the past month in their class. A survey was used because, by Lodigo, Spaulding and Voegtle (2006), it is a method for gathering opinions and perspectives from a rather large population about how the current issue, in this case children's participation, is understood in practical ECEC work in Finland. The congruence of the questionnaire was examined carefully by testing it with 72 ECEC teaching team and evaluated by experts from theoretical and practical understanding about the practices in the field.

The second data set consists of interviews with 3-7-year-old children ( $\mathrm{N}=153)$. Children's initiatives have first been written down in research books (each child had her/his own booklet) 
In: Garvis, S., Harju-Luukkainen, H., Sheridan, S. \& Williams, P. (eds.). Nordic Families, Children and Early Childhood Education. Cham: Palgrave Macmillan, p. 15-36 22 p. (Studies in Childhood and Youth).

through the Action Telling method, which is a participatory and active storytelling method focusing on children's conceptions of their initiatives, interactions, decision-making, and dilemmas they face in early childhood education settings as it promotes children's agency and meaningful problem-solving (Lastikka \& Kangas, 2017). The research was conducted through individual interviews where, instead of questions, children were presented with a set of pictures about their everyday interaction and activities where was a child in front. The researcher asked the interviewee to describe what he/she would do if he/she were that child and wrote down word by word the narration interviewee constructed about the situation. Children decided what should happen next, what to do and with whom to interact. The interviews included the presentation of the research pictures, the child's telling about each picture and finally the read-through of narratives to the child (see Lastikka \& Kangas, 2017). The initiatives were also recorded and documented in a research diary. The data of children's research booklets were copied into a research table where also the recorded interviews were transcribed and additional notes included. This dual record model was used in order to empower children in the data collection phase. The researchers wanted that children did not only have a copy of their answers but that they have their own research books, which were meaningful for them.

The data set was reduced for this study, and the focus was aimed for the children aged 48 to 83 months (4- to 6-year-old children) $(\mathrm{N}=94)$, and the same reduction was made for the data set of the teachers working in classes of 3- to 6-year-old children $(\mathrm{N}=143)$ were selected (in Finland 3-6-year-olds can be in mixed classes). The datasets were read through for this study, and ambiguous questions, remarks and documentations were exposed for the triangulation of this particular research.

\section{Data analysis}

The congruence of the study comes from the abductive analysis approach, which combines the theoretical phenomena, children's participation and motivation theories with the voices of children and teachers. The combination of the theory, analysis, and finally the findings of this research is designed to form a holistic viewpoint to discuss about the phenomenon of children's initiatives with the focus of early childhood education practices. In the process, specific observations and more general processes of such situations are discussed together to determine the aspects of the phenomenon that could be generalized and differ from the others specific to situation itself. In this process, the researchers' understandings of the cultural experience connected to the phenomenon, are essential (Danermark 2001; Kóvach \& Spens 2005).

In the process, the analysis was conducted through the abductive approach, which is considered as a process of intuition or as a kind of systematized creativity in research to create "new" knowledge (Andreewsky \& Bourcier 2000) together with recognizing the voice of participants. Through the abductive approach, children's initiatives were systematically analyzed and the challenges in pedagogical practices of supporting children to express initiatives were identified.

In the analysis process, the both data sets were first read through in order to understand what kind of initiatives teachers' and children were expressing (see figure 1). Then both data sets were coded following a content analysis process with code names like "expressing an idea", "want" or 
In: Garvis, S., Harju-Luukkainen, H., Sheridan, S. \& Williams, P. (eds.). Nordic Families, Children and Early Childhood Education. Cham: Palgrave Macmillan, p. 15-36 22 p. (Studies in Childhood and Youth).

"idea of action". This coding was done in interaction with the theories using abduction to create systematic output. Though this first coding round we defined initiatives as children's wishes, proposals, problem-solving initiatives, questions, and ideas of actions. These codes were classified under three types of activities in classroom: Independent activities (focusing on self), peer-related activities (focusing on peers) and teacher-guided or joint activities with teachers (focusing on teacher). In the table 1, examples of each sub-category can be seen.

Table 1 Examples of coding

\begin{tabular}{|c|c|c|}
\hline & Children's interviews & Survey for teachers \\
\hline Independent activities & $\begin{array}{l}\text { I want to draw. I would take } \\
\text { crayons. }\end{array}$ & Child chooses toys for play time after the meal. \\
\hline Peer-related activities & $\begin{array}{l}\text { Can I join your game? } \\
\text { Let's go to the swings! }\end{array}$ & $\begin{array}{l}\text { Children get excited about constructing games. } \\
\text { They wished that they could build big huts in the } \\
\text { yard. }\end{array}$ \\
\hline $\begin{array}{l}\text { Joint activities with } \\
\text { teachers }\end{array}$ & $\begin{array}{l}\text { I ask teacher to give me that car. } \\
\text { I want to sing imse-vimse-spider in } \\
\text { our music class*. }\end{array}$ & $\begin{array}{l}\text { When a child expresses interest towards a } \\
\text { teacher-guided activity, we may continue the } \\
\text { class* longer than it was planned. }\end{array}$ \\
\hline
\end{tabular}

* In Finnish preschools there are no official "classes". 'Class' is used here for musical circle or related activity moment.

In this process, twelve (7.8\%) interviews of children and thirteen $(9 \%)$ answers from teachers were identified that didn't have any kinds of initiatives described. These were coded as missing cases.

In the next phase, the datasets were read through for the second time (see the Figure 1). They were categorized in three types of focus of action based on the description about was the initiative focused only on child's own activity (like choice of a toy) action, action shared with peer (like joint play) or teacher-initiated activity (like circle time or music class) and three types of target person (self, peers or teacher). 
In: Garvis, S., Harju-Luukkainen, H., Sheridan, S. \& Williams, P. (eds.). Nordic Families, Children and Early Childhood Education. Cham: Palgrave Macmillan, p. 15-36 22 p. (Studies in Childhood and Youth).

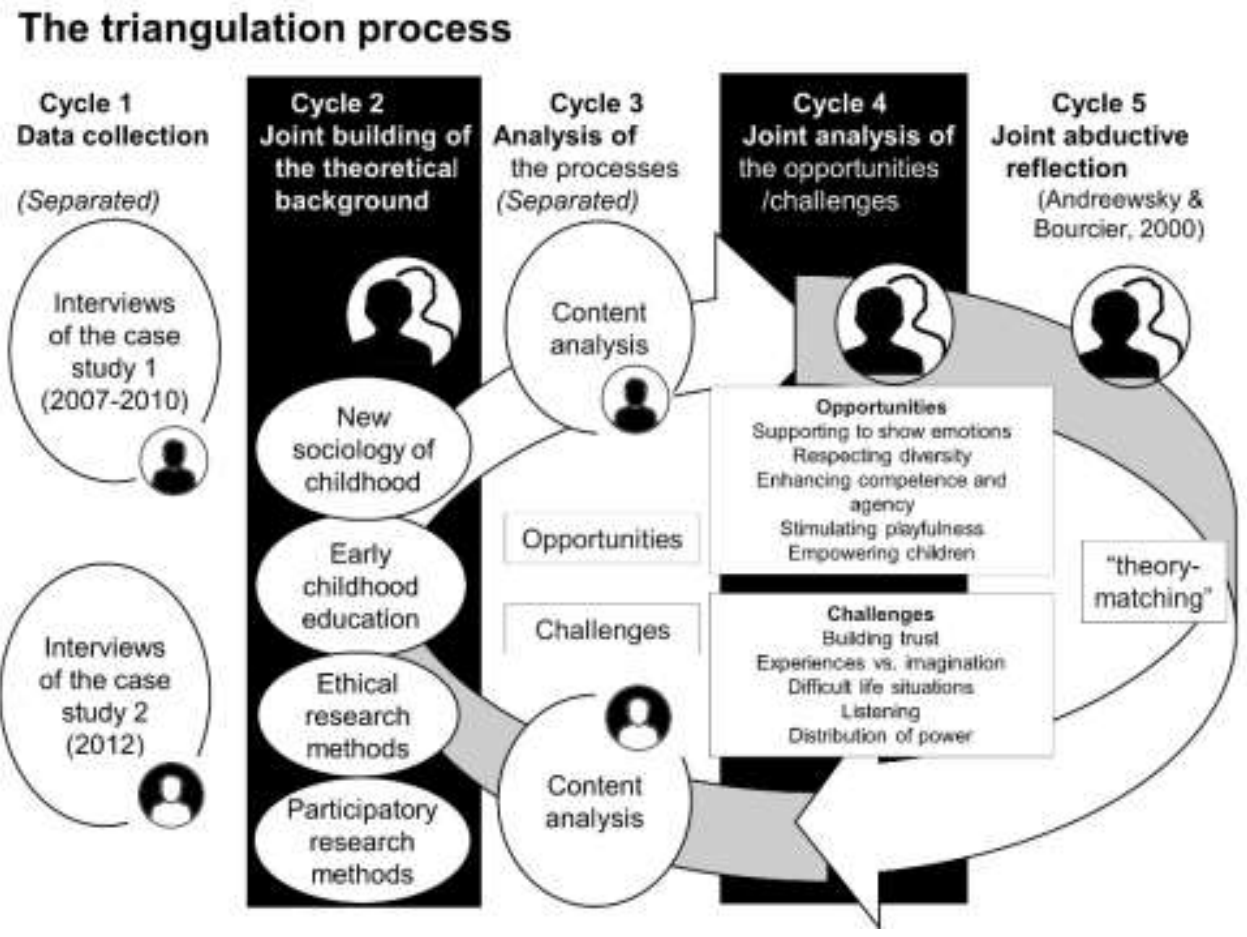

Figure 1 The triangulation process of abductive analysis cycle

In the second phase, the two analysis of different data sets were compared together for creating knowledge about the gaps of participation and observing children's initiatives from the pedagogical point of view. In this process, the actual numbers of codes in each sub-category were compared in a cross-table. Through this process we gained the results about the target persons and focused on activities in children's initiatives.

\section{Children's initiatives in classroom from teachers' and children's perspectives}

In the first part of the results, we will introduce the variety of children's initiatives in early childhood education context classified through the focus of action. In the second part, we map to whom children are expressing their initiatives (the target person), and finally, we bring forward the gaps of participatory practices by comparing these to paths of analysis through cross table.

\section{The focus of action}

All the three sub-categories of the focus of action (self-initiated, peer-related and teacherinitiated) were found in both children's and teachers' answers.

In children's interviews, the self-initiated initiatives were mostly of "inner talk" of children, who explained and described their wishes and choice-making processes. In the first quote, a fiveyear-old girl describes a simple choice-making situation. In the second quote, a rather different way of making initiative is described.

"Here I choose if I paint or draw. I want to draw... a house of ghosts." (girl, 5 years and 4 months) 
In: Garvis, S., Harju-Luukkainen, H., Sheridan, S. \& Williams, P. (eds.). Nordic Families, Children and Early Childhood Education. Cham: Palgrave Macmillan, p. 15-36 22 p. (Studies in Childhood and Youth).

"... the boy didn't want to do anything. He muddled the puzzle, opened books and left the car, doll and ball on the floor." (boy, 5 years and 9 months)

Teachers' description about children's focus of action were mainly targeted on situations where play-based and children-initiated activities were on the schedule. This kind of free play time where children were allowed to choose their toys and playmates is typical in Finnish ECE (see e.g. Leinonen \& al., 2014). These initiatives focused on child's independent actions were about choice-making or expressing a wish or a personal need. For example in the first quote, the teacher describes an initiative about a need, and in the second quote the teacher explains a personal choice-making opportunity.

"Children make initiatives about wishes to discuss or sit in the lap of teacher."

"During the afternoon class children may choose toys and play with them."

In children's interviews, the initiatives related to the focus of peer activities were targeted on shared play. In these children described how the negotiation processes and different ways of making initiatives in everyday interaction (for example one can ask, one can suggest, one can start an activity and invite others in or one can negotiate with peers). The first quote shows a successful way of making an initiative within the play, while the second quote is focused on sharing the responsibility of cleaning toys after play.

'And then I said 'Do we change toys?' and the girl said 'Yes, let's change'. And then I could drive that car." (boy, 5 years and 2 months)

"Then the children clean. So, he needs to clean. Is it fair that he needs to clean by himself? He could say to the girl: Could you clean the toys with me?" (girl, 4 year and 11 months)

Teachers also described children's initiatives towards joint activities with peers emphasized the joint negotiations of children and cases where child would like to join game of others. In the first quote, the teacher describes how discussion with peers ends up to a joint creative activity. In the second quote, the teacher explains the existing way of setting up the focus of action in her classroom.

"The children discuss together about what they have been doing at home and draw and create play characters. "

"The child suggests a game or to play tag... Usually the whole group is inspired by children's ideas e.g. in sport games."

Finally, children described initiatives that were focused on teacher-initiated activities. These focused to situations where children make an initiative by asking help from a teacher. Some rare initiatives were described also where child made an initiative to help teacher, as can be seen in the first quote. Also initiatives, which were based on shared activity between children and adult were described, as in the second quote.

"When this teacher has put these toys on the shelf. That girl wants to help that teacher." (girl, 4 years and 7 months)

"...he made a puzzle and it was wrongly made and he was annoyed by that and he went to ask the teacher for help. And that teacher helped him a little... And then after a little 
In: Garvis, S., Harju-Luukkainen, H., Sheridan, S. \& Williams, P. (eds.). Nordic Families, Children and Early Childhood Education. Cham: Palgrave Macmillan, p. 15-36 22 p. (Studies in Childhood and Youth).

while he did the puzzle again a bit wrongly and he went again to the teacher to ask for help and got help and managed to finish well the puzzle." (boy, 6 years and 2 months)

Children's initiatives focused on the teacher-initiated activities were observed also by teachers. In these children were expressing wishes towards play-based activities, art and craft activities and sports activities to be implemented with teacher(s). For example in the first quote, the teacher explained, how child invites her to join in a play. In the following quote, the teacher describes, how the children's meetings promote participation and support children to express initiatives towards shared activities.

"Often the children ask an adult to join a play and tell adults about their wishes for activities and play."

"In the children's meetings we decide together about things or implement one child's wish about some common activity."

\section{The target person}

Initiatives towards self, peers and teachers were found and categorized from both the children's and teachers' data.

Children's expressed wants and ideas of actions for learning new skills and competences towards themselves, i.e. as inner dialogue. Children told about wanting a certain toy or making a choice between different options, as in this quote of a 5-year-old girl. The second quote shows an example of wish of competence.

"It wonders, why there are so few toys. Then it decides to play with a car. And then it wants to read a book and then it wants to play with barbies." (a girl, 5 years and 9 months)

"I would like to blow bubbles as high as I can." (a boy, 4 years and 10 months)

Teachers expressed observations about initiatives that individual child made about him/her own actions. These independent activities concerned about the choice of toys, the spot of starting a self-initiated play, making independent crafts during classroom time. In the first quote, a teacher describes the practice in her classroom to allow children to regulate their own actions through initiatives. In the second quote, the teacher mentions how a want of a child can lead to an activity.

"During afternoon children can choose themselves activities and friends"

"Children's initiatives for activities are tried to put into practice: e.g. a child wants to sew > we make this possible by taking out sewing materials"

When focusing on peers, children expressed that initiatives could be also directed towards a peer, who was harming others or disturbed play, as the first quote shows. Children also expressed that some of the initiatives were shared with a friend, like in the second quote.

"The other girl is breaking those. You are not allowed to break those. The others try to [say]. 'Don't break'." (girl, 4 years and 11 months)

"Because they want to play, play. They decide that it is fun." (girl, 4 years and 6 months) 
In: Garvis, S., Harju-Luukkainen, H., Sheridan, S. \& Williams, P. (eds.). Nordic Families, Children and Early Childhood Education. Cham: Palgrave Macmillan, p. 15-36 22 p. (Studies in Childhood and Youth).

The initiatives that were aimed to peers were identified from the observations of teachers. These were focusing on shared play activities and games (such as soccer) and sharing about conceptions and knowledge of phenomenon in the society (such as media characters), as in the first quote below. Sometimes teachers also reported peer-focused initiatives about an activity in the middle of teacher-guided activity, as in the second one.

"Children discuss with each other about what they have been playing at home... and develop e.g. play figures and characters."

"In the middle of a gymnastic exercise children invented own tag play and we gathered participants for this great play idea."

Finally, initiatives that were focused on teacher were described by teachers about their person and teacher-guided classroom activities (see the first quote), and also during self-initiated playtime. Teachers also pointed out that some children wished to spend time with the teacher and made initiatives about care and cuddling, as in the second example. This is in line with the recent research of Katsiada et al. (2018) in which children under 3-year-old performed agency in order to initiate and accept or reject warm, sensitive, affectionate and playful interactions with adults in an ECE setting.

"A child wants to perform his own performance and introduce research explorations and realizations."

"Children's initiatives for coming to sit on a lap... are taken into account."

Children expressed initiatives towards teachers by asking questions or making initiatives for help, as can be seen in the first quote. There were also invitations to join in actions, as in the second quote.

"Then the boy shouted: 'Adult! No one plays with me, not a girl, not an adult'." (girl, 4 years and 9 months)

"... tried to reach a car with hands. Then I said to the teacher that 'Could you give me that police car' and she gave and then I said 'Thank you, now I go to play'." (boy, 5 years and 2 months)

\section{The gaps of children's initiatives in pedagogical practices}

We were also interested in studying how children's initiatives were taken into account in pedagogical practices according to children. Here we will introduce cross-tables of different kinds of described initiatives by teachers and children in order to form a holistic view about to what focus of action and to whom children's initiatives are focusing in everyday interaction of ECE. The tables have been conducted by comparing the coded data of focus of action and target person.

The first table (table 1) shows that teacher observe mainly individual children and their personal wishes, but miss initiatives towards peers. They lack of observation, when children are making initiatives about their own or their peers' actions during teacher-guided activities. One challenging issue was also that teachers did not recognize wishes for support from a teacher as initiatives ( $0 \%$ of initiatives towards teacher or peers during a self-initiated activity). If a child is focused on a self-initiated activity, he/she has to solve problems and make decisions on his/her 
In: Garvis, S., Harju-Luukkainen, H., Sheridan, S. \& Williams, P. (eds.). Nordic Families, Children and Early Childhood Education. Cham: Palgrave Macmillan, p. 15-36 22 p. (Studies in Childhood and Youth).

own. Also the percentage of initiatives towards a teacher during peer activities is low (3\%), so if a problematic issue emerges, children are expected to solve it out themselves.

Table 2. Teachers' descriptions about children initiatives

\begin{tabular}{|c|c|c|c|}
\hline & Focus of Action & & \\
\hline Target Person & $\begin{array}{l}\text { SELF-INITIATED } \\
\text { ACTIVITIES }\end{array}$ & $\begin{array}{c}\text { SHARED ACTIVITIES } \\
\text { WITH PEERS }\end{array}$ & $\begin{array}{c}\text { TEACHER- INITIATED } \\
\text { ACTIVITIES }\end{array}$ \\
\hline SELF & $46 \%$ & $9 \%$ & $6 \%$ \\
\hline PEERS & $0 \%$ & $12 \%$ & $6 \%$ \\
\hline TEACHERS & $0 \%$ & $3 \%$ & $12 \%$ \\
\hline
\end{tabular}

In the second table (table 3) about children's initiatives, it can be seen that children make all kinds of initiatives; thus, majority of these were their inner talk to regulate personal wishes and actions by making choices. However, children did express more initiatives towards peers and teachers than the teachers themselves described. For example, in $12 \%$ of interviews, a child expressed an initiative or wish toward peers that was focused on her own action. The lack of teachers' observation in these kind situations (teachers described none of these kinds of activities, see table 2) can cause conflicts between children or even bullying situations.

Table 3. Children's descriptions of their initiatives

\begin{tabular}{|l|c|c|c|}
\hline & Focus of Action & & \\
\hline Target Person & $\begin{array}{c}\text { 1 SELF-INITIATED } \\
\text { ACTIVITIES }\end{array}$ & $\begin{array}{c}\text { 2 SHARED ACTIVITIES } \\
\text { WITH PEERS }\end{array}$ & $\begin{array}{c}\text { 3 TEACHER INITIATED } \\
\text { ACTIVITIES }\end{array}$ \\
\hline 1. SELF & $27 \%$ & $12 \%$ & $11 \%$ \\
\hline 2. PEERS & $13 \%$ & $15 \%$ & $7 \%$ \\
\hline 3. TEACHERS & $6 \%$ & $5 \%$ & $4 \%$ \\
\hline
\end{tabular}

\section{Conclusions}

When comparing teachers' observations and children's conceptions it can be seen that teachers are focused on observing individual children (46\% of all observations) and wishes and initiatives children express. Observed initiatives are generally seen as positive wishes and suggestions, and teachers did not describe controversial initiatives, such as wants that could not been fulfilled. ECE teachers in Finland seem to have adopted children's participation by observing and then supporting their self-initiated activities and teacher-initiated activities (i.e. teaching activities): they recognize and support children's initiatives towards guided classroom activities, for example asking for favorite song to be sung during music class or book to be read in a circle time. These can be seen as acceptable wants or positive initiatives that teachers are willing to answer. Children's other wants, as described by Straughan (1978), are still almost 40 years later not acceptable. However, in general teachers fail to observe some of the initiatives 
In: Garvis, S., Harju-Luukkainen, H., Sheridan, S. \& Williams, P. (eds.). Nordic Families, Children and Early Childhood Education. Cham: Palgrave Macmillan, p. 15-36 22 p. (Studies in Childhood and Youth).

towards them of peers during all types of focus of actions, which may be based on traditional observation and evaluation strategies of an individual child although the new curriculum of ECE in Finland (2016) emphasizes social skills, shared learning and belonging. Therefore, teachers need more observation tools to follow, understand and support children to make initiatives toward their peers.

It is interesting that children also expressed a lot of inner talk $(27 \%)$ about personal wishes and choices. However, when looking at the cross-table (table 3) of children's interviews it is seen that children express all kinds of initiatives more widely than teachers could observe. Children expressed also controversial initiatives (e.g. "Do not take it from me!" Or "I want to be alone!"), which teachers did not mention at all.

\section{Discussion and Implications for Research and Practice}

We share Ødegaard's and Kotliar's (2013) statement that in order to be democratic, there is a requirement for social action: someone has to take children's initiatives into account. Therefore, we have studied in the Finnish ECE context the initiatives children take and teachers' conceptions of children's initiatives.

For example, Sheridan and Pramling-Samuelsson (2001) have found in their research that for young children's participation skills, it is essential to have opportunities to express independent initiatives. Our results show that young children are competent to express initiatives towards different actions and members of their society, and do not hesitate to express also socially less accepted initiatives. However, as research shows (e.g. Kangas, Venninen \& Ojala 2016) young children are not fully controlling their self-regulation and they have wishes and wants that are not always building shared wellbeing. Therefore, teachers support and help in controversial situations would be important; it is unsettling to find out that teachers are not capable of observing the multitude of children's initiatives. Furthermore, with the support of teachers, practices including influence and bearing responsibility with enjoyment and feelings of belonging are crucial for participation skills (see also Leinonen \& Venninen 2012).

Although there is research evidence of participation's positive outcomes and the rights for participation, the research of young children's decision-making processes is still scarce. Additionally, children's voices have been strictly regulated and silenced in educational institutions (Woodhead 2015; Hohti \& Karlsson 2013). In our study, we did not focus on teachers' regulation processes but on the cross-tables about what kind of initiatives were observed i.e. socially accepted showed that certain types of initiatives remain unseen. Although the discourse of a competent child may dominate the educational discourse, it is too simplified to expect that it would be the predominant approach in educational practices (Alasuutari 2014).

Furthermore, as has been discussed earlier, children's initiatives play a crucial role in learning and motivation. Our research implies that in the future, more emphasis should be put on the psychological need of relatedness: children expressed more initiatives towards peers than teachers themselves described. Children also wished to spend time with teachers: to play, to share explorations and to cuddle with them. Feeling belongingness and connectedness with 
In: Garvis, S., Harju-Luukkainen, H., Sheridan, S. \& Williams, P. (eds.). Nordic Families, Children and Early Childhood Education. Cham: Palgrave Macmillan, p. 15-36 22 p. (Studies in Childhood and Youth).

others is clearly important for children (see Hilppö 2016) and their motivation in learning (see also Ryan \& Deci 2000).

In addition, we would like to stress the psychological need of competence, which is important in increasing children's motivation (see also Ryan \& Deci, 2000). Although in our study teachers reported practices, which allow children to regulate their own actions through initiatives, it is essential to promote competence in education in order that children feel that they are capable and able to learn new skills. Therefore, the needs of relatedness and competence should be integral parts of the operational culture of an ECE setting. More detailed research is needed in studying how children's initiatives are considered in early childhood education pedagogy.

Participation can be seen as a developing cultural aspect within the community of children and educators participating in everyday practices (Kangas 2016; Kumpulainen \& al. 2014). In our study, children described their ideas of actions, the process of making initiatives and wants. They also expressed wishes about their growing competence, as telling about the skills they would wish to have. Thus we could build a picture of children as competent meaning-makers, who are eager to interact with peers and teachers and build their skills. This research is in line with previous researches about children as active agent of their own learning (Hilppö 2016; Berthelsen 2009).

Following our results, it would be significant to focus more on children's initiatives in different daily interaction situations in educational settings. In order to understand the processes that nourish motivation and create meaning-making through individual and shared actions, it is essential to focus on children's participation and pedagogical practices aiming to promote children's agency and motivation in ECE. The process, where a wish or a want is transformed as an initiative and further on a process of decision-making is an important part of these participatory practices.

\section{References}

Alasuutari, M. (2014). Voicing the child? A case study in Finnish early childhood education. Childhood, 21(2), 242-259.

Andreewsky, E. \& Bourcier, D. (2000) Abduction in language interpretation and law making. Kybernetes, 29(7/8), 836-845.

Aras, S. (2016). Free play in early childhood education: a phenomenological study, Early Child Development and Care, 186(7), 1173-1184.

Berthelsen, D. (2009). Participatory Learning, In: D. Berthelsen, J. Brownlee, and E. Johansson (Eds.), Participatory learning in the early years: research and pedagogy, New York: Routledge. pp. 1-11.

Cheeseman, S. \& Sumsion, J. (2016). Narratives of infants' encounters with curriculum: The benediction as invitation to participate, Contemporary Issues in Early Childhood, 17(3), 275288.

Cook, D. A. \& Artino, A.R. (2016). Motivation to learn: an overview of contemporary theories, Medical education. DOI:10.1111/medu.13074

Corsaro, W.A. (2011). The sociology of childhood. 3rd edition. CA: Sage Publications. 
In: Garvis, S., Harju-Luukkainen, H., Sheridan, S. \& Williams, P. (eds.). Nordic Families, Children and Early Childhood Education. Cham: Palgrave Macmillan, p. 15-36 22 p. (Studies in Childhood and Youth).

Danermark, B. (2001). Explaining Society: An Introduction to Critical Realism in the Social Sciences, Routledge, Florence, KY.

De Ro'iste, A., Kelly, C., Molcho, M., Gavin, A. \& Gabhainn, N. (2011). Is school participation good for children? Associations with health and wellbeing. Health Education, 112(2), 88-104.

Early Childhood Education and Care Act (2015).

Einarsdottir, J., Purola, A-M., Johansson, E.M, Broström, S. \& Emilson, A. (2015). Democracy, caring and competence: values perspectives in ECEC curricula in the Nordic countries. International Journal of Early Years Education, 2015, 23(1), 97-114.

Finnish National Agency for Education (2016). The National Core Curriculum for early years.

Fredriksen B. C. (2010). Meaning making, democratic participation and art in early childhood education: Can inspiring objects structure dynamic curricula? International Journal of Education through Art, 6(3), 381-395.

Hatch, A. J. (2013). Back to Modernity? Early Childhood Qualitative Research in the 21th Century. In A.J. Hatch (eds.) Early Childhood Qualitative Research. pp. 7-18. NY:Routlege.

Hilppö, J. (2016). Children's Sense of Agency: A Co-Participatory Investigation (doctoral dissertation). University of Helsinki.

Hohti, R. \& Karlsson, L. (2013). Lollipop stories: Listening to children's voices in the classroom and narrative ethnographic research. Childhood, 21(4), 548-562.

Kangas, J. (2016). Enhancing children's participation in early childhood education with participatory pedagogy. Helsinki: Unigrafia.

Kangas, J., Venninen, T. \& Ojala, M. (2016). Educators' Perceptions of Facilitating Children's Participation in Early Childhood Education. Australasian Journal of Early Childhood. 41(2), 85-94.

Karila, K. (2012). A Nordic Perspective on Early Childhood Education and Care Policy. European Journal of Education, 47(4), 584-595.

Karlsson, L., Weckström, E., \& Lastikka, AL. (2018). Osallisuuden toimintakulttuuria rakentamassa sadutusmenetelmällä [Creating the operational culture of participatory through the Storycrafting method]. In J. Kangas, J. Vlasov, E. Fonsén. \& J. Heikka. (eds.) [Participatory pedagogy in early childhood education 2: Planning, implementation and developing] (pp. 7399). Tampere: Suomen Varhaiskasvatus ry.

Katsiada, E., Roufidou, I., Wainwright, J. \& Angeli, V. (2018). Young children's agency: exploring children's interactions with practitioners and ancillary staff members in Greek early childhood education and care settings. Early Child Development and Care, 188(7), 937-950,

Kovács, G. and Spens, K.M. (2005). Abductive reasoning in logistics research. International Journal of Physical Distribution \& Logistics Management, 35(2), 132-44.

Kumpulainen, K., Lipponen, L., Hilppö, J. \& Mikkola, A. (2014). Building on the positive in children's lives: a co-participatory study on the social construction of children's sense of agency. Early Child Development and Care, 184(2), 211-229.

Lastikka, A-L., \& Kangas, J. (2017). Ethical Reflections of Interviewing Young Children: Opportunities and Challenges for Promoting Children's Inclusion and Participation. Asia-Pacific Journal of Research in Early Childhood Education, 11(1), 85-110.

Leinonen, J. \& Venninen, T. (2012). Designing learning experiences together with children. Procedia: Social and Behavioral Sciences, 45, 466-474. 
In: Garvis, S., Harju-Luukkainen, H., Sheridan, S. \& Williams, P. (eds.). Nordic Families, Children and Early Childhood Education. Cham: Palgrave Macmillan, p. 15-36 22 p. (Studies in Childhood and Youth).

Lodigo, M. G., Spaulding, D.T. \& Voegtle, K.H. (2006). Methods in Educational Research. From Theory to Practice. CA: Jossey-Bass.

Mayall, B. (1999). Children and childhood. In S. Hood, B. Mayall, \& S. Oliver (Eds.), Critical issues in sociology research Buckingham, UK: Open University Press. pp. 10-24.

Odegaard, E., \& Kotliar, I. (2013). Kindergarten as an arena for cultural formation. CulturalHistorical Psychology, 2, 29-30.

Piaget, J. (1976). The child's construction of reality. London: Routledge.

Rogoff, B. (2008). Observing sociocultural activity on three planes: Participatory appropriation, guided participation, and apprenticeship. In: K. Hall, P. Murphy \& J. Sole (eds.) Pedagogy and Practice: Culture and Identities. CA: Thousand Oaks. pp. 58-74.

Rutanen, N. (2012). Socio-spatial practices in a Finnish daycare group for one- to three-year olds. Early Years, 32(2), 201-214.

Ryan, R.M. \& Deci, E.L. (2000). Self-Determination Theory and the Facilitation of Intrinsic Motivation, Social Development, and Well-Being. American Psychologist, 55(1), 68-78.

Sheridan, S. \& Pramling-Samuelsson, I. (2001). Children's conception of participation and influence in pre-school: a perspective of pedagogical quality. Contemporary Issues in Early Childhood 2(2), 169-194.

Shier, H. (2001). Pathways to Participation: Openings, Opportunities and Obligations. Children \& Society, 15, 107-117.

Straughan, R. (1978). Children's Wants. Journal of Philosophy of Education, 12, 149-155.

Thomas, N. \& O'Kane, C. (1998). The Ethics of Participatory Research with Children. Children \& Society, 12, 336-348.

Vygotsky, L. (1978). Mind and society: the development of higher psychological processes. Boston, MA: Harvard University Press.

Woodhead, M. (2015). Psychology and the cultural construction of children's needs. In A. James \& A. Prout (eds.) Constructing and reconstructing childhood. CA: Routledge. pp. 72-91. 